\title{
Effects of exposure to microwaves on cellular immunity and placental steroids in pregnant rats
}

Department of Public Health, Kanazawa University School of Medicine,

Takaramachi 13-1, Kanazawa 920, Japan H Nakamura

H Nagase

M Yoshida

$S$ Dan

K Ogino

Department of

Physiology (I),

Kanazawa University

School of Medicine,

Takaramachi 13-1,

Kanazawa 920, Japan

Toshio Seto

Correspondence to: Dr Hiroyuki Nakamura, Department of Public

Health, Kanazawa University School of Medicine,

Takaramachi 13-1, Kanazawa 920, Japan.

Accepted 26 February 1997

Hiroyuki Nakamura, Toshio Seto, Hirofumi Nagase, Masami Yoshida, Shigun Dan, Keiki Ogino

Abstract

Objectives-Microwaves produce various detrimental changes based on actions of heat or non-specific stress, although the effects of microwaves on pregnant organisms has not been uniform. This study was designed to clarify the effect of exposure to microwaves during pregnancy on endocrine and immune functions.

Methods-Natural killer cell activity and natural killer cell subsets in the spleen were measured, as well as some endocrine indicators in blood-corticosterone and adrenocorticotrophic hormone (ACTH) as indices of the hypothalamic-pituitaryadrenal axis- $\beta$-endorphin, oestradiol, and progesterone in six female virgin rats and six pregnant rats (nine to 11 days gestation) exposed to microwaves at $10 \mathrm{~mW} /$ $\mathrm{cm}^{2}$ incident power density at $2450 \mathrm{MHz}$ for 90 minutes. The same measurements were performed in control rats (six virgin and six pregnant rats).

Results-Skin temperature in virgin and pregnant rats increased immediately after exposure to microwaves. Although splenic activity of natural killer cells and any of the subset populations identified by the monoclonal antibodies CD16 and CD57 did not differ in virgin rats with or without exposure to microwaves, pregnant rats exposed to microwaves showed a significant reduction of splenic activity of natural killer cells and CD16+CD57-. Although corticosterone and ACTH increased, and oestradiol decreased in exposed virgin and pregnant rats, microwaves produced significant increases in $\beta$-endorphin and progesterone only in pregnant rats.

Conclusions-Microwaves at the power of $10 \mathrm{~mW} / \mathrm{cm}^{2}$ produced activation of the hypothalamic-pituitary-adrenal axis and increased oestradiol in both virgin and pregnant rats, suggesting that microwaves greatly stress pregnant organisms. These findings in pregnant rats suggest thatwith exposure to microwaves-pregnancy induces immunosuppression, which could result in sucessful maintainance of pregnancy. This enhancement of adaptability to heat stress with pregnancy may be mediated by activation of placental progesterone and placental or pituitary $\beta$-endorphin.
(Occup Environ Med 1997;54:676-680)

Keywords: microwaves; heat stress; pregnancy; natural killer cell activity; $\beta$-endorphin

Microwaves are electromagnetic waves ranging in frequency from $300 \mathrm{MHz}$ to $300 \mathrm{GHz}$ and used for communication-for example, communication cover radar, television, and radio relay of telephone and telegraph messages as well as for industry, medicine, and homes. Some reactions to exposure to microwaves may lead to measurable biological effects that remain within the range of normal physiological compensation and are not necessarily hazardous, or some improve the efficiency of certain physiological processes and can thus be used for therapeutic purposes. Some reactions, on the other hand, may lead to effects that are potentially or actually hazardous to health. ${ }^{1}$ The heating effect of microwaves on the testes has been studied extensively. ${ }^{2}$ Ocular effects of microwaves are considered to be due to heating action as a physical stressor. ${ }^{3}$ Autonomicendocrine changes induced by microwaves are based on non-specific emotional stress. ${ }^{45}$ Effects of microwaves on pregnant organisms have not been consistant. ${ }^{16}$

Pregnancy produces adaptative modifications to the homeostasis of the maternal immune system in the survival of the fetoplacental graft. ${ }^{78}$ Natural killer cells act early in the immune response before specificity can be generated. They mediate the first line of defence by direct cytotoxicity against various types of target cells without apparent previous immunisation. ${ }^{9}$ Reduced natural killer cytolytic activity in pregnant women has been shown to be an adaptive change in immune function. ${ }^{10}{ }^{11}$ Thus effects of exposure to microwaves on neuroimmunity during pregnancy may differ from those during non-pregnancy.

To examine the involvement of pregnancy in endocrine and immune functions after exposure to microwaves, we measured natural killer cell activity and natural killer cell subsets in the spleen cells, as well as some endocrine indicators in blood-corticosterone and adrenocorticotrophic hormone (ACTH)-as indices of the hypothalamic-pituitary-adrenal axis; $\beta$ -endorphin, oestradiol, and progesterone in female virgin rats and pregnant rats exposed to microwaves at $10 \mathrm{~mW} / \mathrm{cm}^{2}$ incident power density at $2450 \mathrm{MHz}$ 


\section{Materials and methods}

PREPARATION OF VIRGIN AND PREGNANT RATS

FOR STUDY

Twelve virgin female Wistar rats that had a mean (SD) weight of 290 (16.4) g and 12 Wistar rats at nine to 11 days of gestation that weighed 296 (18.5) g were studied. Breeding was performed by introducing a male rat into a cage with two females. The environment was controlled in all cases $\left(23(2)^{\circ} \mathrm{C}, 50 \%\right.$ humidity, and alternating cycles of 12 hours of light (8 $00 \mathrm{am}-800 \mathrm{pm}$ ) and 12 hours of darkness. The onset of pregnancy was determined with vaginal smears. All animals had free access to commercial food and tap water. The rats were fasted, but given water for 24 hours before the experiment and were deprived of food and drink throughout the experiment. This study was approved by the ethics committee on Animal Experimentation of Kanazawa University, Takara-machi Campus. In all cases the experimental protocol began at $1100 \mathrm{am}$.

\section{EXPOSURE TO MICROWAVES}

The method of exposure has already been described. $^{5}$ The microwave generator was equipped with a magnetron of $2450 \mathrm{MHz}$ as the source of energy and had an isolator to control the variability of energy from the magnetron induced by reflection from the applicator $(350 \times 470 \times 455 \mathrm{~mm})$. Six virgin rats and six pregnant rats were put into a semicylindrical acrylic plastic holder (thickness $5 \mathrm{~mm}$; inside diameter $60 \mathrm{~mm}$; length $170 \mathrm{~mm}$ ) and were exposed to microwaves at $10 \mathrm{~mW} / \mathrm{cm}^{2}$ incident power density at $2450 \mathrm{MHz}$ for 90 minutes. The control rats (six virgin rats and six pregnant rats) were treated in an identical manner except that the microwave generator was not turned on. During exposure, the environment was maintained at $21-23^{\circ} \mathrm{C}$ and $50-60 \%$ humidity.

The specific absorption rates for each power density were obtained from the dosimetry handbook. ${ }^{12}$ This handbook has both calculated and measured values which agree very closely for rats exposed to $2450 \mathrm{MHz}$ plane wave fields. For a medium size rat $(320 \mathrm{~g})$ oriented parallel to the electromagnetic field, the mean specific absorption rate was about 0.22 $\mathrm{mW} / \mathrm{g}$ for each $\mathrm{mW} / \mathrm{cm}^{2}$ incident power density. For a rat oriented perpendicular to the electromagnetic field the specific absorption rate was about $0.18 \mathrm{~W} / \mathrm{kg}$ for each $\mathrm{mW} / \mathrm{cm}^{2}$ incident power density. Therefore, for an incident power density of $10 \mathrm{~mW} / \mathrm{cm}^{2}$ the mean whole body specific absorption rate would range from $1.8-2.2 \mathrm{~W} / \mathrm{kg}$.

\section{MONITORING OF SKIN TEMPERATURE}

The rat's tail was inserted through the $T$ connector and the tip of the tail was taped to the plate. A temperature probe (Toshiba Electronics, Tokyo, Japan) was inserted through the open side of the $T$ connector, perpendicular to the long axis of the tail. Skin temperature was monitored just before exposure ( 0 minutes), and $15,30,45,60$, and 75 minutes after the start, and immediately after the end of the exposure (90 minutes). Exposure to micro- waves was stopped temporarily for each measurement.

MEASUREMENTS OF PLASMA CORTICOSTERONE, ACTH, $\beta$-ENDORPHIN, OESTRADIOL, AND PROGESTERONE

Blood samples were collected by decapitation of rats immediately after the end of the protocol. Plasma was immediately prepared by transfer of samples to cooled conical centrifuge tubes containing $0.1 \mathrm{mM}$ EDTA which were then centrifuged. Plasma was frozen at $-80^{\circ} \mathrm{C}$ until analyses were performed.

Corticosterone was measured by the fluorometric method of Silber et al, ${ }^{13}$ and ACTH was measured by radioimmunoassay as described by Orth. ${ }^{14} \beta$-Endorphin was measured by the radioimmunoassay described by Yoshimi et al. ${ }^{15}$ For this method, highly purified human $\beta$-endorphin, labelled with $\mathrm{Na}^{125} \mathrm{I}$ using chloramine $T$, was purified on a carboxymethyl cellulose column. The antiserum against $\beta$-endorphin showed negligible cross reactivity with other fragments of $\beta$-lipotropin such as $\alpha$-melanocyte stimulating hormone and ACTH.

Oestradiol and progesterone were analysed by radioimmunoassay using the tube solid phase method of Ratcliffe et al. ${ }^{16}$

ACTIVITY OF NATURAL KILLER CELLS AND

NATURAL KILLER CELL SUBSETS

To measure splenic activity of natural killer cells, the spleen was surgically excised and dissociated into a single cell suspension. The splenocytes were suspended in $40 \mathrm{ml}$ phosphate buffered saline and centrifuged in $50 \mathrm{ml}$ tubes at $400 \mathrm{~g}$ at room temperature for $30 \mathrm{~min}$ utes over $12 \mathrm{ml}$ Ficoll-Paque (Pharmacia, Piscataway, NJ, USA) to yield mononuclear cells. ${ }^{17}$ Splenic lymphocytes were collected at the interface, washed twice in phosphate buffered saline solution, and suspended in Roswell Park Memorial Institute 1640 medium (Gibco, Grand Island, NY, USA) supplemented with $10 \% \mathrm{v} / \mathrm{v}$ fetal bovine serum (FBS, GIBCO), $2 \mathrm{mM}$ L-glutamine, $100 \mathrm{U} / \mathrm{ml}$ penicillin, and $100 \mu \mathrm{g} / \mathrm{ml}$ streptomycin, all from Gibco.

Activity of natural killer cells was measured in a standard four hour chromium (Cr) release assay that was performed in $0.2 \mathrm{ml}$ volumes in $\mathrm{U}$ bottomed microplates. The YAC-1 mouse lymphoma cell line was used as the target for detecting cytotoxicity of natural killer cells. The cells, suspended in culture in Roswell Park Memorial Institute 1640 medium, were labelled with $\mathrm{Na}_{2}{ }^{51} \mathrm{CrO}_{4}$ at $1 \mathrm{mCi} / \mathrm{ml}$ (New England Nuclear, Boston, MA, USA) for one hour at $37^{\circ} \mathrm{C}$. Cells were washed four times in a tissue culture medium consisting of Roswell Park Memorial Institute 1640 and resuspended in fresh medium, counted, and aliquoted at $1 \times$ 104 target cells/well into 96 well U bottomed microtitre plates containing lymphocytes as effector cells at predetermined concentrations. The effector:target cell ratios used were 40:1, 20:1, 10:1, and 5:1. After plates were incubated in $5 \% \mathrm{CO}_{2}$ in air at $37^{\circ} \mathrm{C}$ for four hours, the reactions were stopped by centrifuging the 
plate at $400 \mathrm{~g}$ for five minutes after which the medium was harvested from each well with a supernatant harvesting apparatus (Flow, McLean, VA, USA). All measurements were done in triplicate. Radioactivity was counted in a gamma counter. The spontaneous ${ }^{51} \mathrm{Cr}$ release, measured by incubating labelled target cells in the medium alone, did not exceed $10 \%$ of the maximum release that was found by adding $1 \%$ TritonX100. Activity of natural killer cells was measured as percentage specific lysis according to the formula:

$100 \times$ (mean experimental counts per minute (cpm) - mean spontaneous cpm)/ (mean maximal cpm - mean spontaneous release $\mathrm{cpm}$ ).

The percentage cytotoxicity was calculated at each effector:target cell ratio, and these values were converted to lytic units at $30 \%\left(\mathrm{LU}_{30}\right)$ according to the method of Pross et al. ${ }^{18}$

Total lymphocytes were counted by standard techniques with a microscope haemocytometer on a smear of the splenocyte suspension stained with trypan blue. Two major monoclonal antibodies that recognise natural killer cell surface antigens were chosen for the two colour flow cytometry: (a) CD16 (antiLeu11) against the $\mathrm{Fc}$ receptor present in human large granular lymphocytes, and (b) CD57 (antiLeu7/H natural killer-1) against a subset of natural killer cells. Thus, the flow cytometric study generated three subsets of natural killer cells: (a) CD16+CD57-, (b) CD16+CD57+, (c) CD16-CD57+.

\section{STATISTICAL ANALYSIS}

Skin temperature at each time point was compared with the value before the exposure by the paired $t$ test. Statistical analysis of the differences in the mean values of splenic activity of natural killer cells and CD16,CD57 subsets, and blood variables among the four groups were performed by one way analysis of variance (ANOVA), followed by the Tukey test for multiple comparisons. All statistical tests were two tailed. $P$ values $<0.05$ were regarded as significant.

\section{Results}

CHANGE IN SKIN TEMPERATURE INDUCED BY EXPOSURE TO MICROWAVES

The figure shows changes in skin temperature in virgin and pregnant rats with and without exposure to microwaves. The increase in skin temperature in both groups exposed to microwaves reached significance after 15 minutes

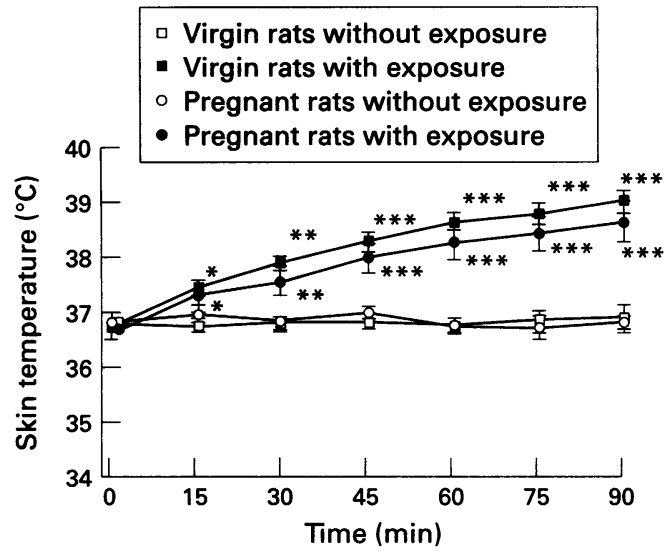

Effects of exposure to microwaves on tail skin temperature in virgin and pregnant rats. Values are mean (SEM).

Significant difference from the value before exposure, ${ }^{\star} P<0.05,{ }^{\star} P<0.01,{ }^{\star \star *} P<0.001$ v values before exposure.

when compared with the value before exposure. The Tukey test showed no significant difference at any time in increases in skin temperature between the virgin and pregnant rats exposed to microwaves.

CHANGE IN SPLENIC ACTIVITY OF NATURAL KIILER CELLS AND CD16CD57 SUBSETS

Significant differences were not detected in splenic weight, absolute number of splenic lymphocytes, or populations of any lymphocyte subsets excluding CD16+CD57- among the four groups, but the CD16+CD57- population was significantly decreased by microwaves in the pregnant rats. Splenic activity of natural killer cells in the virgin rats exposed to microwaves did not differ from that of unexposed rats. However, the pregnant rats exposed to microwaves showed a significant reduction of splenic activity of natural killer cells. Comparison of splenic activity of natural killer cells between virgin and pregnant rats without exposure to microwaves did not show immunosuppression induced by pregnancy (table 1).

CHANGES IN BLOOD CORTICOSTERONE, ACTH, $\beta$-ENDORPHIN, OESTRADIOL, AND PROGESTERONE Although a significant increase in corticosterone and ACTH and decreases in oestradiol were recognised in the exposed virgin and pregnant rats, microwaves produced significant increases in $\beta$-endorphin and progesterone only in the pregnant rats (table 2). When the blood indicators were compared between virgin and pregnant rats without exposure, pregnancy was found to increase oestradiol and progesterone.

Table 1 Effects of exposure to microwaves on splenic weight, absolute number of splenic lymphocytes, and populations of CD16CD57 subsets and activity of natural killer cells in virgin and pregnant rats

\begin{tabular}{|c|c|c|c|c|c|c|c|}
\hline \multirow[b]{2}{*}{ Rat group } & \multirow[b]{2}{*}{$\begin{array}{l}\text { Rats } \\
\text { examined (n) }\end{array}$} & \multicolumn{6}{|c|}{ Values (mean (SEM)) } \\
\hline & & Splenic weight $(g)$ & $\begin{array}{l}\text { Total } \\
\text { lymphocytes in } \\
\text { spleen }\left(\times 10^{7}\right)\end{array}$ & $\begin{array}{l}C D 16-C D 57+ \\
(\%)\end{array}$ & $\begin{array}{l}C D 16+C D 57+ \\
(\%)\end{array}$ & $\begin{array}{l}C D 16+C D 57- \\
(\%)\end{array}$ & $\begin{array}{l}\text { Activity of } \\
\text { natural killer } \\
\text { cells }\left(L U_{30}\right)\end{array}$ \\
\hline Virgin without exposure & 6 & $0.71(0.053)$ & $21.7(0.90)$ & $6.72(1.51)$ & $23.5(0.83)$ & $12.0(0.97)$ & $7.62(0.84)$ \\
\hline Virgin with exposure & 6 & $0.70(0.029)$ & $20.7(1.32)$ & $8.70(1.23)$ & $20.0(4.71)$ & $12.6(0.81)$ & $6.65(1.21)$ \\
\hline Pregnant without exposure & 6 & $0.71(0.029)$ & $21.3(0.85)$ & $6.63(1.69)$ & $19.6(3.47)$ & $10.3(1.71)$ & $7.23(1.43)$ \\
\hline Pregnant with exposure & 6 & $0.71(0.041)$ & $21.4(1.33)$ & $7.58(1.31)$ & $16.7(1.92)$ & $7.91(1.34)^{\star}$ & $3.75(0.89)^{\star}$ \\
\hline
\end{tabular}

$\star \mathrm{P}<0.05$ exposed $v$ non-exposed rats by one way ANOVA, then by the Tukey test for multiple comparisons. 
Discussion

The heat action of microwaves has been used in women to treat gonorrhoea, pelvic inflammatory disease, endomekiosis, carcinoma of the uterus, and pelvic peritonitis. However, some case reports point out the limits of the use of microwaves for pregnant women. ${ }^{19} 20$ Some epidemiological studies suggest harmful effects of microwaves on the normal course of pregnancy; ${ }^{21}$ others do not support a causal relation between exposure to microwaves and abnormalities in pregnancy. ${ }^{1}$ Some evidence showing a direct relation is available, but specific effects of microwaves on pregnant organisms remain to be elucidated. ${ }^{16}$

Immunosuppression during pregnancy produces adaptations in the homeostasis of the maternal immune system relevant to the survival of the fetoplacental graft. ${ }^{11}{ }^{11}$ Although this study did not show a reduction in activity of natural killer cells associated with pregnancy, it should be noted that activity of natural killer cells and CD16+CD57subsets during exposure to microwaves were decreased only in the pregnant rats. As the subset of natural killer cells bearing CD16+ surface antigen is reported to be the most potent in cytolysis of target tumour cells, whereas the CD57+ subset is reported to be less potent, ${ }^{22}$ our results indicate a decrease in cellular immunity in the pregnant rats exposed to microwaves. Increased skin temperature induced by microwaves coincides well with our previous reports, ${ }^{5}$ showing that microwaves used in this study were strong heat stressors. Heat stress during early or midpregnancy results in a high incidence of embryonic mortality. ${ }^{23}{ }^{24}$ Restraint stress decreases the concentration of serum progesterone in pregnant rats, suggesting that restraint stress is luteolytic and causes fetal loss during pregnancy. ${ }^{25} 26$ Exposure to microwaves produced increases in corticosterone and ACTH in the pregnant rats as well as in the virgin rats. It can, therefore, be considered that the hypothalamic-pituitary-adrenal axis is activated by exposure to microwaves during pregnancy as well. This implies that exposure to microwaves acts on pregnant organisms as a harmful stressor, thereby interfering with the natural course of pregnancy. However, we found increased progesterone during exposure to microwaves in the pregnant rats, indicating that such exposure does not seem to cause luteinising dysfunction during pregnancy. Progesterone and oestradiol are mostly of ovarian origin in non-pregnant women. During pregnancy the placenta takes over as the main site of synthesis of these hormones from maternal and fetal precursors ${ }^{27}$ as progesterone and oestradiol rise dramatically. ${ }^{8}$ Influence on the activity of the immune system by sex hormones has been widely reported under physiological conditions. ${ }^{28}{ }^{29}$ Progesterone at concentrations found in the human placenta acts as an immunosuppressive agent on lymphocyte cultures stimulated by allogenic antigen. ${ }^{30}$ Increased progesterone as well as decreased activity of natural killer cells and decreased CD16+CD57- found only in pregnant rats suggest that placental progesterone participates in the regulation of the immunity in an adaptive response to exposure to microwaves during pregnancy.

Likewise, $\beta$-endorphin was increased by exposure to microwaves only in the pregnant rats. The cytotoxicity of splenic natural killer cells is suppressed in rats exposed to opioid dependent stress. As this decrease in activity of natural killer cells is blocked by naloxone, endogenous opioids are apparently involved. ${ }^{31}$ As well as immunosuppression induced by $\beta$-endorphin, ${ }^{32}$ several studies have shown that circulating $\beta$-endorphin increases in pregnant women..$^{34}$ The increase is related in part to secretion by the placenta, ${ }^{35}$ but otherwise is dependent on hypersecretion by the anterior pituitary gland. ${ }^{36}$ Although the role of increased $\beta$-endorphin in neuroimmunity during pregnancy remains to be elucidated, a negative correlation between activity of natural killer cells and $\beta$-endorphin in non-pregnant and pregnant rats exposed to heat suggests that activation of placental functions including increased progesterone produced by exposure to microwaves leads to immunosuppression. Such mechanisms during heat stress seem to reinforce homeostasis against the heat stressor. This activates the hypothalamic-pituitaryadrenal axis, especially through enhancement of adaptative ability.

Data from animal experiments cannot be directly extrapolated to humans due to their physiological differences and their physical dimension and shape. However, an effort has been made to standardise dosimetric measures of exposure to microwaves by using the specific absorbtion rate which is applicable to any organ of interest or different sizes of laboratory animals and humans. ${ }^{12} \mathrm{~A}$ specific absorbtion rate of $1.8-2.2 \mathrm{~W} / \mathrm{kg}$, which is calculated by transformation of $10 \mathrm{~mW} / \mathrm{cm}^{2}$ used in the present study, would seem to be much greater than $0.40 \mathrm{~W} / \mathrm{kg}$ which is recommended as the maximum permissible exposure level by the

Table 2 Effects of exposure to microwaves on blood indicators in virgin and pregnant rats

\begin{tabular}{|c|c|c|c|c|c|c|}
\hline \multirow[b]{2}{*}{ Rat group } & \multirow{2}{*}{$\begin{array}{l}\text { Rats } \\
\text { examined } \\
\text { (n) }\end{array}$} & \multicolumn{5}{|c|}{ Blood indicators (mean (SEM)) } \\
\hline & & $\begin{array}{l}\text { Corticosterone } \\
(\mathrm{ng} / \mathrm{ml})\end{array}$ & $A C T H(p g / m l)$ & $\begin{array}{l}\text { B-endorphin } \\
(p g / m l)\end{array}$ & $\begin{array}{l}\text { Oestradiol } \\
(\mathrm{pg} / \mathrm{ml})\end{array}$ & $\begin{array}{l}\text { Progesterone } \\
(\mathrm{pg} / \mathrm{ml})\end{array}$ \\
\hline Virgin without exposure & 6 & $187(18.5)$ & $323(24.6)$ & $82.7(10.1)$ & $38.4(6.16)$ & $264(38.3)$ \\
\hline Virgin with exposure & 6 & $310(38.7)^{\star}$ & $483(51.1)^{\star}$ & $98.3(7.19)$ & $20.3(2.60)^{\star}$ & $386(38.1)$ \\
\hline Pregnant without exposure & 6 & $232(21.7)$ & $330(31.5)$ & $83.3(9.24)$ & $56.5(4.60) t$ & $424(28.6) \dagger$ \\
\hline Pregnant with exposure & 6 & $346(37.8)^{\star}$ & $478(40.7)^{\star}$ & $135(22.2)^{\star}$ & $39.5(5.05)^{\star}$ & $606(70.7)^{\star}$ \\
\hline
\end{tabular}

$\star \mathrm{P}<0.05 v$ the rat group with the same condition except for exposure by one way ANOVA, then by the Tukey test for multiple comparisons.

$\nmid \mathrm{P}<0.05 v$ the virgin rats without exposure. 
American National Standards Institute. ${ }^{37}$ However, it has been suggested that exposure to near field microwaves may be more dangerous to humans. ${ }^{1}$ Taking together the physiological and anatomical differences between pregnant and non-pregnant bodies, it seems likely that the results obtained from our experimental design with microwaves of $10 \mathrm{~mW} / \mathrm{cm}^{2}$ can lead to assessment of the effects of most actual exposures to microwaves. Although our study focused on the pathogenetic mechanisms for endocrine and immune functions in the pregnant rats exposed to microwaves, effects of microwaves of various levels and frequencies on the course of pregnancy should be tested by further studies. The present study has shown mainly thermal effects of microwaves on pregnancy, and we note the need to examine non-thermal or specific effects of microwaves at the molecular and cellular level. ${ }^{1}$ In future work it will be necessary to clarify specific effects on endocrine and immune functions during pregnancy.

In conclusion, our study showed that microwaves at the power $10 \mathrm{~mW} / \mathrm{cm}^{2}$ produced an activation of the hypothalamic-pituitaryadrenal axis and increased oestradiol in both virgin and pregnant rats, suggesting that microwaves act on pregnant organisms as harmful stressors. The results found only in pregnant rats suggest that, with exposure to microwaves, pregnancy induces immunosuppression which could result in sucessfully maintaining pregnancy. This adaptability to heat stress during pregnancy may be mediated by activation of placental progesterone and placental or pituitary $\beta$-endorphin.

This work was supported in part by a grant in aid for scientific research (C; No 07670431) from the Ministry of Education Science and Cultures, of Japan for 1995-1996. We are indebted to the president of Kanazawa University, Dr Akira Okada, for his kind support and interest regarding this work.

1 Michaelson SM. Health implications of exposure to radiofrequency/microwave energies. $\mathrm{Br} f$ Ind $\mathrm{Med}$ 1982;29:105-19.

2 Leonard A, Berteaud AJ, Bruyere A. An evaluation of the mutagenic, and teratogenic potential of microwaves. Mutat Res 1983;123:31-46.

3 Lipman RM, Tripathi BJ, Tripathi RC. Cataracts induced by microwave and ionizing radiation. Surv Ophthalmol by microwave and

4 Michaelson SM, Houk WH, Lebda NJA, Lu ST, Magin R. Biochemical and neuroendocrine aspects of exposure to Biochemical and neuroendocrine aspects of ex
microwaves. Ann NYAcad Sci 1975;247:21-45.

microwaves. Ann $N$ Y Acad Sci 1975;247:21-45.
5 Inaba R, Shishido K, Okada A, Moroji T. Effects of whole body microwave exposure on the rat brain contents of biogenic amine. Eur $\mathcal{F}$ Appl Physiol 1992;65:124-8.

6 Brent RL. The effect of embryonic and fetal exposure to $x$ rays, microwaves, and ultrasound: counseling the pregnant and nonpregnant patient about these risks. Semin Oncol 1989;16:347-68.

7 Jacobi DR, Olding LB, Oldstone MBA. Immunologic regulation of fetal maternal balance. Adv Immunol 1984;35: 157-208.

8 Branch DW. Physiologic adaptations of pregnancy. Am $f$ Reprod Immunol 1992;28:120-22.

Trinchieri G. Biology of natural killer cells. Adv Immunol 1989;47:187-376.

10 Gregory CD, Shah LP, Lee H, Scott IV, Golding PR. Cytotoxic reactivity of human natural killer (NK) cells during normal pregnancy: a longitudinal study. f Clin Lab Immunol 1985;18:175-81.
11 Salmeron OJ, Vaquer S, Salmeron I, Molto L, Lapena P, Manzano L, et al. Pregnancy is associated with a reduction in the pattern of the cytotoxic activity displayed by in the pattern of the cytotoxic activity displayed by lymphokine-acti

12 Dumey CH, Johnson CC, Barber PW, Massoudi $H$, Iskander MF, Lords $\mathrm{JL}$, et al. Radiofrequency radiation dosimetry handbook. 2nd ed. Brooks Air Force Base, TX: USAF School of Aerospace Medicine, 1978. (SAM-TR78-22.)

13 Silber RH, Busch RD, Oslapas R. Practical procedure for estimation of corticosterone or hydrocortisone. Clin Chem $1958 ; 4: 278-85$

14 Orth DN. Adrenocorticotropic hormone (ACTH). In: Jaffe BM, Behrman HR, eds. Methods of hormone radioimmunoassay. New York, Academic Press, 1979:245-50.

15 Yoshimi H, Matsukawa S, Sueoka S, Fukae M, Yokota M, Hirata Y, Imura H. Radioimmunoassay for $\beta$-endorphin: presence of immunoreactive "big-big" $\beta$-endorphin ("big" presence of immunoreactive "big-big" $\beta$-endorphin ("big" 2189-95.

16 Ratcliffe WA, Carter GD, Dowsett M, Hillier SG, Middle JG, Reed MJ. Estradiol assays: applications and guidelines for the provision of a clinical biochemistry service. Ann Clin Biochem 1988;25:466-83.

17 Reynolds CW, Timonen T, Herberman RB. Natural killer cell activity in the rat: isolation and characterization of the celfector cells. $\mathcal{F}$ Immunol 1981;127:282-7.

18 Pross HF, Baines MG, Rubin P, Shragge P, Patterson MS Spontaneous human lymphocyte-mediated cytotoxicity against tumor target cells. IX. The quantitation of natural killer cell activity. $\mathcal{F}$ Clin lmmunol 1981;1:51-63.

19 Gellhorn S. Diathermy in gynecology. $¥ A M A$ 1928;90. 1005-8.

20 Rubin A, Erdman WJ. Microwave exposure of the human female pelvis during early pregnancy and prior to concepfemale pelvis during early pregnancy
tion. Am $\mathcal{F}$ Phys Med 1959;38:219-20.

21 Silverman C. Epidemiologic studies of microwave effects. Proc Inst Electrical Electronics Engineers 1980;68:78-84.

22 Lanier LL, Le AM, Phillips JH, Warner NL, Babcock GF. Subpopulations of human natural killer cells defined by expression of the Leu-7 (HNK-1) and Leu-11 (NK-15) antigens. F Immunol 1983;131:1789-96.

23 Alliston CW, Ulberg LC. Early pregnancy loss in sheep at ambient temperatures of 70 and $90^{\circ} \mathrm{F}$, as determined by embryo transfer. $\mathcal{F}$ Anim Sci $1961 ; 20: 608-11$.

24 Thwaites CJ. Embryo mortality in the heat stressed ewe. I. the influence of breed. $\mathcal{F}$ Reprod Fertil 1967;14:5-14.

25 Wiebold JL, Stanfield PH, Becker WC, Hillers JK. The effect of restraint stress in early pregnancy in mice. $\mathcal{F}$ Reprod Fertil 1986;78:185-92.

26 Sugino N, Nakamura Y, Okuno N, Shimamura K, Teyama $T$, Ishimatsu M, Kato $H$. Effects of restraint stress on luteal function in rats during mid-pregnancy. $\mathcal{f}$ Reprod Fertil function in rats

27 Ryan KJ. Placental synthesis of steroid hommones. In: Tulchinsky D, Ryan KJ, eds. Maternal-fetal endocrinology. Philadelphia: WB Saunders, 1980.

28 Inman RD. Immunologic sex differences and the female predominance in systemic lupus erythematosus. Arthritis Rheum 1978;21:849-52.

29 Giglio T, Imro MA, Filaci G, Scudeletti M, Puppo F, De Cecco L, et al. Immune cell circulating subsets are affected by gonadal function. Life Sci 1994;54:1305-12.

30 Grossman CJ. Interactions between the gonadal steroids and the immune system. Science 1985;227:257-61.

31 Shavit Y, Terman GW, Martin FC, Lewis JW, Liebeskind JC, Gale RP. Stress, opioid peptides, the immune system, and cancer. $\mathcal{F}$ Immunol $1985 ; 135: 834 S-7 S$.

32 Mori T, Kaizaka Y, Hori T, Nakashima T. Effects of intracerebral injection of $\beta$-endorphin on the cytotoxic activity of natural killer cells in the spleen. Fpn f Physiol 1989; 39(suppl):s118.

33 Weber RI, Pert A. The periaqueductal grey matter mediates opiate-induced immunosupression. Science 1989;245:18890.

34 Newnham PJ, Tomlin S, Ratter SJ, Bourne GL, Rees LH. Endogenous opioid peptides in pregnancy. Br $\mathcal{f}$ Obstet Gynaecol 1983,90:535-8.

35 Nakai Y, Nakao K, Oki S, Imura, I. Presence of immunoreactive $\beta-\mathrm{LPH}$ and $\beta-\mathrm{EP}$ in human placenta. Life Sci 1978; 23:2013-8.

36 Petraglia F, Baraldi M, Giarre G, Facchinetti F, Santi M, Volpe A, Genazzani AR. Opioid peptides of the pituitary and hypothalamus: changes in pregnant and lactating rats. and hypothalamus: changes in

37 American National Standards Institute. Safety levels with respect to human exposure to radiofrequency electromagnetic fields ( $300 \mathrm{kHz}$ to $300 \mathrm{GHz}$ ). New York: ANSI, 1990; ANSI C95.1. 